\title{
Note on Transliteration
}

The only standard system for the transliteration of the Greek alphabet into languages written in Latin characters is that used for the transliteration of classical Greek. The transliteration of ancient Greek, however, is quite inappropriate for rendering the spelling and especially the phonetics of modern Greek. Accordingly the following modifications have been introduced to make it conform more to the modern morphology and sound of the language. Diphthongs have generally been retained, except in those cases where the modern pronunciation of Greek requires a consonant to be adequately rendered (for example, "aftou" not "autou"). The Greek vowels $\eta$ and $\imath$ have been uniformly rendered with $i$, and similarly o and $\omega$ have been rendered with $o$. The Greek $v$ has been rendered with $y$, except when it forms part of a diphthong; then it is rendered by $u$ (for example, "tou"). The rough breathing has been dropped.

Consonants have generally been rendered phonetically. Thus the Greek $\beta$ has been rendered by the Latin $v$ rather than $b$. The Greek consonant $\varphi$ is rendered by $p h$ in all words with an ancient Greek root. Conversely, Greek names with Latin roots (such as Constantinos) have been transliterated as closely as possible to their original form.

We have generally followed the monotonic accentuation system in force in Greece today for the spelling of Modern Greek, but we have respected individual authors' use of the polytonic system in cases where such a preference occurs in the text of their essays.

The names of modern Greek authors appear in the form used by the authors themselves if they have published work in a foreign language. Inevitably some inconsistencies will remain, but we hope the reader will find this understandable in a book of this nature. Place names have been used in their standard forms 
in the English language, otherwise they have been transliterated following the general rules adopted in this book.

Words and terms originating in the Turkish language as well as Turkish names have been used in the conventional forms established by usage in English-language writing. In some cases diacritics have been added to help pronunciation of these linguistic forms. 